\title{
ATUAÇÃO DAS AGÊNCIAS REGULADORAS NAS CONCESSŐ̃ES DE RODOVIAS NO BRASIL: IMPLICAÇÕES DO PROBLEMA AGENTE-PRINCIPAL
}

\author{
PERFORMANCE OF REGULATORY AGENCIES IN ROAD \\ CONCESSIONS IN BRAZIL: IMPLICATIONS OF THE AGENT- \\ PRINCIPAL PROBLEM
}

\author{
Graciela Aparecida Profeta \\ Universidade Federal Fluminense - Campos dos Goytacazes - RJ - Brasil \\ Viviani Silva Lírio \\ Universidade Federal de Viçosa - Viçosa - MG - Brasil \\ Elke Silva Santos \\ Campos dos Goytacazes - RJ - Brasil
}

\begin{abstract}
Resumo: Os serviços de infraestrutura pública têm sido ofertados pela iniciativa privada com participação do Estado por meio de agências reguladoras setoriais. Contudo, pela existência dos problemas típicos da relação agente-principal, que marcam esses acordos, há questionamentos quanto à atuação eficiente dessas agências. O objetivo deste estudo foi apresentar e discutir as características intrínsecas da atuação das agências reguladoras e como estão susceptíveis a influências políticas e a problemas de captura. O estudo mostrou que, apesar de serem autarquias com independência financeira e administrativa, há pontos importantes de frouxidão no regime de atuação das agências, principalmente os ligados à nomeação/indicação dos conselheiros pelos respectivos governos e à subordinação orçamentária. Tais aspectos sinalizam a possibilidade da captura e influência política, o que pode afetar a eficiência no setor. Todavia, apesar de carecer de reformulação e aparato legal, a atuação das agências é importante para a garantia da eficiência, uma vez que o setor de concessões de rodovias no Brasil é concentrado e isso pode permitir ação oportunista de empresas e governos no momento das licitações.

Palavras-chave: Agência reguladora. Problema agente-principal. Eficiência.
\end{abstract}

\begin{abstract}
Public infrastructure services have been offered by private companies with state participation through sectoral regulatory agencies. However, due the existence of typical problems of Agent-Principal relationship that sign these arrangements, there are questions related to efficient performance of these agencies. In this sense, the objective was to present and discuss the intrinsic characteristics of the performance of the regulatory agencies, and how they are susceptible to political influence and capture problems. It was concluded that despite authorities with financial and administrative independence, there are important points of laxity in the agencies acting regime, especially those ones linked to the nomination / appointment of certain directors from their government and to budget subordination. These aspects indicate the possibility of capture and political influence, which can affect the efficiency in the sector. However, despite lack of reformulation and law enforcement, the performance of the agencies is important for ensuring efficiency because the highway concessions sector in Brazil is concentrated and this may allow the opportunistic behavior of firms and governments at the time of bidding.
\end{abstract}

keywords: Regulatory agency. The principal-agent problem. Efficiency. 


\section{INTRODUÇÃO}

O setor de transportes é um importante meio pelo qual o investimento público pode contribuir para o crescimento econômico de um país. Os serviços de infraestrutura, incluindo estradas, são fundamentais para a operação e eficiência de uma economia moderna e apresentam significativo impacto na produtividade e competitividade empresariais. Por esse motivo, o investimento adequado e o aumento da eficiência nesse setor são cruciais para aprimorar as condições de vida da população como um todo e, particularmente, em um país de renda média e geograficamente vasto como o Brasil.

Em razão disso, os serviços de infraestrutura têm sido objeto de intervenção do setor público, seja pela atuação direta de entidades estatais ou por meio de concessões à iniciativa privada. Todavia, segundo Crew e Kleindorfer (2002), a grande questão é que as concessões se caracterizam como situações de monopólios naturais ${ }^{1}$ e, portanto, necessitam de regulação para evitar a ineficiência e proteger os consumidores de sua exploração.

Isso ocorre porque, ao transferir à iniciativa privada os serviços de infraestrutura, o Estado acaba por envolver três diferentes agentes - o usuário, o investidor e o regulador - cujos objetivos nem sempre são coincidentes e, nessas circunstâncias, cria-se um ambiente favorável a conflitos de interesses. Portanto, conforme Pires e Piccinini (1999), a regulação deve se sustentar em um conjunto de regras que visem a incentivar e a garantir os investimentos necessários à participação privada, promover o bem-estar dos consumidores e usuários e aumentar a eficiência econômica.

Contudo, segundo Di Pietro (2004), esta não é uma tarefa simples, visto que o processo regulatório se desenvolve em ambiente sustentado por duas ideias contraditórias. Por um lado, a concessão é um serviço que deve ser feito de acordo com o interesse público, sob a autoridade do Estado; no entanto, esse serviço é operacionalizado por um concessionário com interesses de investidor privado. Nesse sentido, a contradição se dá pela necessidade de serem mantidos o interesse público e o equilíbrio econômico-financeiro da concessionária durante o período do contrato. Portanto, pela complexidade da atuação do regulador, houve necessidade de serem criadas agências reguladoras que atuassem de forma independente em relação a todos os agentes envolvidos, de modo a garantir a defesa do bem-estar da sociedade e mediar conflitos entre investidores, consumidores e governo.

Entretanto, a criação desses órgãos levanta questões que vão desde aquelas relacionadas aos custos associados à sua atuação, até aquelas inerentes à independência do processo decisório, que está intimamente ligado à sua independência. Cabe destacar que a independência das agências está diretamente relacionada à autonomia financeira, diretorias estáveis, corpo técnico especializado

\footnotetext{
${ }^{1}$ De acordo com Viscusi et al. (2000), o monopólio natural ocorre quando a produção de um bem ou serviço por uma única empresa minimiza os custos. Todavia, dado que o monopolista não é price-taker, isto é, não aceita o preço definido pelo mercado, pelo contrário, tem poder de determinar o preço, seus serviços apresentarão um preço maior do que se ele estivesse em um mercado competitivo.
} 
e transparência, bem como a uma definição clara de suas funções e atribuições, garantidas por um marco regulatório existente.

Desse modo, tais discussões têm posto em dúvida a real importância da regulação para o setor de infraestrutura de serviço público na garantia da eficiência. Se, por um lado, acredita-se que as agências reguladoras sejam capazes de garantir que as empresas privadas operem de modo eficiente e com isso assegurar resultados semelhantes aos dos mercados competitivos; por outro lado, alguns autores como Ekelund e Hérbert (1981), Chadwick (1859), Demsetz (1968) e Posner (1972) defenderam outros mecanismos de concessão, como, por exemplo, o mecanismo de mercado, leilão, apontando que estes sistemas seriam mais eficientes do que a regulação e ainda teriam custo irrisório para a sociedade, tornando a regulação desnecessária.

Nesse sentido, deve-se questionar se, de fato, a ação regulatória, via agências, no setor de concessões no Brasil, apresenta falhas que prejudiquem a eficiência no setor, de tal modo que este mecanismo deva ser substituído por outro, como, por exemplo, pelo mecanismo de mercado, leilão, proposto por Demsetz (1968). Para responder a tal questionamento, foram apresentadas as características intrínsecas da atuação das agências reguladoras de concessões no Brasil, segundo elementos da teoria do agente-principal, como a assimetria de informação e captura, e como essas agências estão susceptíveis às influências políticas.

\section{O PROBLEMA DO AGENTE-PRINCIPAL E SUAS IMPLICAÇÕES PARA A REGULAÇÃO NO SETOR DE CONCESSÕES DE RODOVIAS NO BRASIL}

As relações econômicas bilaterais entre um indivíduo ou mais (principal) e outro (agente) são marcadas pela autonomia decisória dos agentes e pelo fato de as ações dos agentes afetarem não apenas seu bem-estar, mas o de outras partes que possam estar envolvidas na relação. Isso implica dificuldade de acompanhamento das ações dos agentes por parte do principal. Tais características constituem o foco da teoria do Agente-Principal.

Nesse sentido, conforme destacam Jensen e Meckling (1976), a teoria do agente-principal trata do relacionamento entre agentes nas trocas econômicas, em que um ator (o principal) tem poder sobre o comportamento de outro ator (o agente) em seu favor, e o bem-estar do principal sofre influência das decisões do agente. Assim, os problemas relacionados à teoria do agente-principal surgem quando há conflito entre as partes envolvidas².

No caso dos serviços de infraestrutura de rodovias no Brasil, a retomada do processo de concessão traz à tona o problema do agente-principal, na medida em que o poder público (principal) delega serviços às empresas privadas (agentes) e não tem condições de monitorar adequadamente sua ação, seja por assimetria de informações entre as partes, seja por falta de experiência na realização das atividades delegadas ou ainda pela impossibilidade de controlar todas as ações dos agentes. Nessas circunstâncias, muitas vezes, as decisões dos agentes divergem dos

\footnotetext{
2 Para mais detalhes sobre o problema agente-principal, ver Jensen e Meckling (1976), Hatch (1997), Arrow (1985), Clegg, Hardy e Nord (1996).
} 
objetivos perseguidos pelo principal.

Segundo Câmara (2006), no caso das agências reguladoras, entidades localizadas no centro de um sistema composto pelo poder público, usuários e concessionárias, e cuja função é dirimir conflitos entre tais atores, sua posição é ao mesmo tempo de agente e principal. A atuação como agente ocorre quando se considera a função de regulador do sistema, já a atuação como principal é visualizada quando a agência define suas relações com as concessionárias.

Nesse caso, observa-se certa ambiguidade em relação ao papel da agência reguladora que deve, concomitantemente, atender aos interesses do bem-estar social e os interesses dos particulares, de modo a alcançar a eficiência setorial. Há de se destacar também que a agência não é uma entidade inerte nesse sistema triangular; ela também tem interesses próprios, muitas vezes, divergentes dos objetivos do poder público e, obviamente, do proprietário da empresa, o que torna sua atuação ainda mais complexa.

\section{A ATUAÇÃO DA AGÊNCIA FEDERAL - ANTT}

A Agência Nacional de Transportes Terrestres - ANTT foi instituída em 5 de junho de 2001 e regulamentada em 13 de fevereiro de 2002. Trata-se de uma entidade integrante da administração federal indireta, submetida ao regime autárquico especial, o que lhe confere personalidade jurídica de direito público, independência administrativa, autonomia financeira e funcional e mandato fixo de seus dirigentes, vinculado ao Ministério dos Transportes.

No que se refere à exploração de rodovias ${ }^{3}$, a ANTT tem qualidade de órgão regulador e, atualmente, é responsável pela regulação de 21 concessionárias de rodovias, cujos trechos administrados somam $6.852 \mathrm{~km}$ de extensão. São elas: Novadutra, Ecoponte, Concer, CRT, Concepa, Ecosul, Planalto Sul, Litoral Sul, Régis Bittencourt, Fernão Dias, Fluminense, Transbrasiliana, Rodovia Aço, Viabahia, Eco101, MGO e Concebra, CRO (Rota Oeste), MGvias, Via040 e Rodovias Galvão.

Além disso, essa autarquia apresenta independência decisória, cujo órgão supremo é a diretoria colegiada que atua de forma coordenada a outros órgãos subordinados a ela. Os dirigentes são escolhidos pelo Presidente da República e por ele nomeados após aprovação do Senado Federal, não podendo ser exonerados pelo Presidente da República discricionariamente, a não ser por processo administrativo disciplinar; isto é, se cometerem faltas funcionais, ou de condenação judicial transitada e julgada.

Portanto, os dirigentes têm algo parecido com a estabilidade temporária, durante o período em que exercem a função, o que reforça o caráter de independência da agência. Contudo, segundo Prado (2005), apesar de ser uma importante garantia de independência, a estabilidade no cargo pode não ser efetiva na medida em que o Presidente da República pode atuar politicamente junto ao diretor, convencê-lo a renunciar ao cargo e, por esta razão, nomear um

\footnotetext{
${ }^{3}$ Vale lembrar que, conforme Guerra (2012), constituem esferas de atuação da ANTT o transporte ferroviário de passageiros e cargas, o transporte rodoviário interestadual e internacional de passageiros e cargas e o transporte multimodal.
} 
substituto conivente com sua vontade. Esses procedimentos de ingerência são, de fato, pontos críticos no processo de regulação.

Na estrutura organizacional da ANTT, também existem tantos outros órgãos subordinados à diretoria colegiada, responsáveis por áreas de execução de projetos, auditoria, ouvidoria, outorgas, pesquisas etc. Portanto, tal estrutura exige que as decisões sejam tomadas por um grupo, não somente por um indivíduo; o que, a princípio, leva a crer que essa estrutura possa dificultar a possibilidade da captura do agente regulador pelo particular.

Entretanto, há de se ressaltar o que determina o artigo 10 da Resolução no 3.000, de 28 de janeiro de 2009, do Regimento Interno da ANTT: "As decisões da Diretoria serão tomadas pelo voto da maioria absoluta de seus membros, cabendo ao diretor-geral o voto de qualidade". Com isso, cabe ao diretor geral o poder do desempate, quando acontecer, o que o deixa em posição de destaque, podendo ser, por esta vazão, alvo de investidas de particulares.

Então, apesar de apresentar características tais como decisão colegiada, poder normativo, autonomia financeira, independência, entre outras, que sinalizam para uma atuação imparcial e eficiente, ainda existem questões que merecem destaque por reduzir a capacidade dessa agência em, de fato, atuar a favor da eficiência. Em relação a isso, sabe-se que um dos pressupostos para que a agência atue de forma independente está justamente na sua autonomia orçamentária. No caso da ANTT, está previsto no seu Regimento Interno, no artigo 14, que o orçamento anual da agência deve ser submetido ao Ministério dos Transportes. Portanto, as atividades da agência são financiadas também pelo Ministério dos Transportes, além de recursos próprios oriundos de taxas de fiscalização, multas etc. Dessa forma, a autonomia financeira na prática é limitada e isso implica perda de independência da agência, uma vez que ela pode, em determinadas circunstâncias, agir em benefício do seu patrocinador.

Outra questão a se considerar diz respeito à capacidade técnica da agência. Segundo estudo de Veron e Cellier (2010) sobre a participação privada no setor rodoviário no Brasil, houve reformulação do quadro de pessoal da ANTT, em que técnicos experientes, remanescentes de órgãos como a Rede Ferroviária Federal S.A. - RFFSA e o Grupo Executivo de Integração da Política de Transportes GEPOIT $^{4}$, foram substituídos por um quantitativo considerável de jovens que necessitam de intenso treinamento para se tornarem mais operacionais. Assim, essa fase de reformulação de pessoal, que naturalmente ocorre de tempos em tempos, pode levar a perdas de eficiência nos processos operacionais da agência e, consequentemente, afetar a eficiência das concessões federais.

A respeito disso, no estudo de Veron e Cellier (2010), há menção clara em relação à necessidade de fortalecimento da governança e, para isto, os autores apontaram ser indispensável revisar as estruturas salariais da agência de modo a atrair e recrutar profissionais tão qualificados quanto os dos setores privados.

\footnotetext{
${ }^{4}$ A RFFSA era uma sociedade de economia mista integrante da Administração Indireta do Governo Federal, vinculada funcionalmente ao Ministério dos Transportes. Por sua vez, o GEIPOT era um órgão de apoio técnico e administrativo aos órgãos do Poder Executivo com atribuições de formular, orientar, coordenar e executar a política nacional de transportes nos seus diversos modais, bem como promover, executar e coordenar atividades de estudos e pesquisas necessárias ao planejamento de transportes no País.
} 
Destacaram, ainda, ser primordial que os diretores e gerentes da ANTT sejam selecionados de forma consistente, com base em suas competências técnicas e de gestão, independentemente de interesses políticos e privados.

Outro ponto relevante que deve ser considerado, uma vez que pode afetar a eficiência da atuação das agências e da operação das concessionárias, diz respeito à redação dos contratos. Segundo o Tribunas de Contas da União - TCU (2007), é muito importante a precisão da redação dos contratos e dos editais de modo a garantir a clareza de seus termos, evitando, com isso, comportamentos oportunistas de suas partes em relação à interpretação do contrato, o que pode afetar diretamente o nível de investimentos nas concessões. Sobre esse ponto, cabe comentar que a questão dos contratos e editais de licitação que compõem o leilão de concessões de serviços públicos foi objeto da crítica ao leilão de Demsetz feita por Williamson (1976). Segundo esse autor, o leilão, mecanismo de mercado defendido por Demsetz (1968) em detrimento da regulação por agências, também pode falhar pela incompletude dos contratos e oportunismo dos agentes, tanto no momento da licitação quanto nos períodos de revisão e reajuste tarifário.

A eficiência também pode ser prejudicada se o setor for concentrado, visto que, neste tipo de estrutura, existem relações de interdependência entre as empresas e, no extremo, possibilidade de conduta anticompetitiva, como a formação de cartéis. De acordo com estudo do TCU (2005), a ANTT não acompanha a interdependência entre as empresas que operam no setor de transporte rodoviário, o que prejudica a concorrência efetiva, a melhoria dos serviços prestados e a redução das tarifas cobradas dos usuários.

A informação de qualidade também é um fator que possibilita a eficiência no setor. Todavia, segundo estudo do TCU (2005), a ANTT não dispõe de informações suficientes para avaliar o desempenho operacional, financeiro e contábil das empresas. Portanto, em um ambiente de informação assimétrica, dado que as empresas sabem muito mais do seu negócio do que a agência, não há como garantir que as licitações, renegociações e reajustes tarifários ocorram de forma a atingir a máxima eficiência.

Por fim, os problemas relacionados ao desenho dos contratos de concessão, à formação de grupos dominantes, que aumentam a possibilidade de presença de cartéis, e à escassez de informações, principalmente de cunho técnico, também podem ocorrer nas agências que atuam em âmbito estadual.

\section{A ATUAÇÃO DAS AGÊNCIAS ESTADUAIS}

No Brasil, no que concerne à regulação de rodovias, paralelamente à ANTT no nível federal, que é unissetorial, há ainda outras agências unissetorias em âmbito estadual: Agência Reguladora de Serviços Públicos Concedidos de Transportes Aquaviários, Ferroviários e Metroviários e de Rodovias do Estado do Rio de Janeiro - AGETRANSP/RJ; Agência Reguladora de Transportes do Estado de São Paulo - ARTESP/SP; e Agência Reguladora de Serviços Públicos Delegados de Infraestrutura do Paraná - AGEPAR/PR. Ainda, na esfera estadual, há outras duas, que são multissetoriais: a Agência Reguladora do Estado da Bahia AGERBA/BA e a Agência Estadual de Regulação dos Serviços Públicos Delegados do Rio Grande do Sul - AGERGS/RS. 
No caso da AGERBA, no que diz respeito a concessões de rodovias, cabe a responsabilidade de regular as seguintes concessões: Concessionária Litoral Norte CLN, ViaBahia e Bahia Norte. De acordo com Villalba et al. (2010), a AGERBA, uma das primeiras agências do país, foi instituída e regulamentada em 1998.

Assim como a ANTT, a AGERBA tem a natureza de autarquia sob regime especial, com personalidade jurídica de direito público. Portanto, apresenta autonomia administrativa e financeira, patrimônio próprio, tendo por finalidade regular, controlar e fiscalizar a qualidade dos serviços públicos concedidos, permissionados e autorizados, nos segmentos de energia, transportes e comunicações da Bahia. Além disso, de acordo com o seu Regimento Interno, a AGERBA tem um conjunto de atribuições e competências que the permitem promover e zelar pela eficiência econômica e técnica dos serviços públicos delegados submetidos à sua competência regulatória, propiciando condições de qualidade, regularidade, continuidade, segurança, atualidade, universalidade e modicidade das tarifas.

A AGERBA conta, na sua estrutura organizacional, com um conselho consultivo, órgão de representação da sociedade, que tem competência formal para se manifestar sobre o plano de metas das entidades reguladas e sobre as políticas dos diferentes segmentos dos serviços regulados. Além do conselho consultivo, as decisões da AGERBA são tomadas pela diretoria, em regime de colegiado, formada pelos Diretores Executivos do departamento de qualidade e serviços e do departamento de tarifas e pesquisas socioeconômicas, nomeados pelo governador. Cabe destacar que o fato de a diretoria ser composta por membros nomeados pelo governador pode levar a problemas de captura da agência, de modo que a agência atue em prol dos interesses do governo e não somente com o intuito de garantir os direitos da coletividade e a eficiência dos setores por ela regulados.

Além disso, outra questão importante para a garantia da atuação eficiente da agência é sua capacidade técnica. Em relação a isso, segundo Villalba et al. (2010), uma parcela considerável dos funcionários da agência é proveniente do Departamento de Transporte e Tráfego - DTT e do Departamento de Infraestrutura de Transportes da Bahia - DERBA, sendo que alguns foram transferidos, outros, cedidos. Logo, esse pode ser um ponto positivo quanto à atuação da agência na regulação das concessões de rodovias no Estado, visto que se acredita que tais funcionários tenham certa experiência na área de atuação.

Sabe-se também que o sucesso da ação regulatória está diretamente relacionado ao grau de autonomia da agência, seja financeiro e/ou políticoadministrativo. No que tange a esse aspecto, conforme Villalba et al. (2012), a AGERBA tem algum grau de autonomia financeira, uma vez que suas principais fontes de receita são provenientes: i) de dotações orçamentárias, ii) do percentual incidente sobre o faturamento obtido pelas empresas reguladas, iii) das taxas decorrentes do exercício de fiscalização, entre outras. Com relação à autonomia político-administrativa da AGERBA, a autora aponta "para a existência de relações complexas dentro desta agência e os atores externos envolvidos, sejam os consumidores, o governo ou concessionárias, e isto revela a dificuldade para atingir a autonomia política".

Portanto, em relação à autonomia, seja financeira ou política da AGERBA, o que se verificou é que esta característica não se traduz em ponto forte da agência 
na garantia da eficiência. Pelo contrário, o fato de essa agência depender, por exemplo, de receitas obtidas por meio de percentual do faturamento das concessionárias por ela reguladas abre espaço para a captura. Além disso, como visto, há problemas também quanto à autonomia administrativa. Sendo assim, tais constatações são consideradas fatores que podem contribuir para a atuação distorcida da agência; ou seja, em prol de um grupo de interesse e não da coletividade. Adicionalmente, esse comportamento não só se revelaria inadequado para o funcionamento da própria agência, mas também sinalizaria fragilidade institucional para os atores desse segmento de mercado, o que reduz a possibilidade de investimentos privados.

Outra agência reguladora, fruto de investigação neste trabalho, é a AGETRANSP/RJ, criada em 2005. A AGETRANSP é responsável pela regulação dos contratos de cinco concessionárias estaduais de rodovias: Supervia, Metrôvia, CCRBarcas, Via Lagos e Rota 116.

Conforme Regimento Interno, são algumas competências da AGENTRANSP: i) assegurar a prestação de serviços adequados, em condições de regularidade, continuidade, eficiência, segurança, atualidade, generalidade, cortesia na sua prestação e modicidade nas suas tarifas; ii) garantir a harmonia entre os interesses dos usuários, concessionários dos serviços públicos estaduais regulados; iii) zelar pelo equilíbrio econômico-financeiro dos contratos de concessão; iv) cumprir e fazer cumprir a legislação específica relacionada aos serviços regulados; v) fixar, reajustar, revisar, aprovar e homologar tarifas, seus valores e estruturas; e vi) entre outras.

São inúmeras as funções da AGETRANSP, assim como ocorre para as demais agências mencionadas. Cabe à AGETRANSP, entre outras atribuições, a responsabilidade de mediar conflitos, fiscalizar o cumprimento dos contratos de concessões e garantir a eficiência. Para tanto, a agência conta com um conselho diretor formado por cinco membros indicados pelo governador do Estado, com mandato de quatro anos, cabendo a um deles a presidência do conselho. Então, em razão do poder conferido aos membros do conselho diretor e de serem nomeados pelo governador do Estado, é possível, mesmo sob penalidades, que eles ajam em prol da estabilidade e de benefícios próprios e atuem na defesa do interesse do Estado ou das empresas e não na garantia da eficiência no setor e interesse da coletividade.

Para auxiliar o conselho diretor em suas atividades, a AGETRANSP conta, em sua estrutura organizacional, com as câmaras técnicas. Por determinação do Regimento Interno, essas câmaras deverão ser gerenciadas por profissionais de nível superior, com experiência profissional e técnica na área de atuação da respectiva câmara, comprovada em curriculum vitae. No caso do segmento de transportes e rodovias, o órgão técnico responsável é a Câmara Técnica de Transportes e Rodovias - CATRA.

Ressalta-se que não existem apontamentos no Regimento Interno da AGETRANSP em relação à seleção desses gerentes das câmaras técnicas, a não ser as considerações acerca de sua formação e experiência profissional. Tal fato concede margem para se pensar que a escolha destes gerentes pode ocorrer de forma arbitrária e tendenciosa, o que dá espaço para a existência dos males causados pela captura, uma vez que esses gerentes podem ser instrumento de garantia dos interesses particulares. 
No caso do Estado de São Paulo, tem-se a ARTESP/SP, criada em 2002, responsável pela regulação dos contratos de 19 concessionárias: Autoban, Autovias, Centrovias, Ecovias, Intervias, Renovias, Rodovia das Colinas, SPVias, Triângulo do Sol, Tebe, Vianorte, Viaoeste, CART, Ecopistas, Rodovias do Tietê, Rota das Bandeiras, SPMar, Viarondon e Rodoanel Oeste.

Segundo o Regimento Interno, a ARTESP foi instituída como autarquia de regime especial, dotada de autonomia orçamentária, financeira, técnica, funcional, administrativa e poder de polícia, com a finalidade de regulamentar e fiscalizar todas as modalidades de serviços públicos de transporte autorizados, permitidos ou concedidos a entidades de direito privado, no âmbito da Secretaria de Estado de Logística e Transportes. Portanto, dadas as características acima, acredita-se ser mais difícil a ocorrência da captura regulatória nas concessões paulistas e isso pode permitir maior eficiência no setor.

$\mathrm{Na}$ condição de órgão regulador, compete à ARTESP regulamentar e fiscalizar todas as modalidades de serviços públicos de transportes delegados a entidades de direito privado, no âmbito da Secretaria de Estado dos Transportes. Para tanto, a agência conta com uma estrutura organizacional formada pelos seguintes órgãos: diretoria geral, conselho consultivo, comissão de ética, conselho diretor, ouvidoria, procuradoria, chefia de gabinete, diretoria de assuntos institucionais, diretoria de controle econômico-financeiro, diretoria de investimentos, diretoria de operações e diretoria de procedimento e logística.

O órgão central da ARTESP é a diretoria geral, autoridade superior da agência, que exerce o poder de representação e comando hierárquico sobre o pessoal e os serviços, bem como a relação com a comunidade, o planejamento e a coordenação das demais áreas da ARTESP. O diretor geral faz parte do conselho diretor, constituído por mais cinco diretores, todos nomeados pelo governador, com mandatos fixos e não coincidentes de quatro anos, permitida uma recondução. Novamente, no que concerne à nomeação dos membros do conselho diretor, cabe crítica quanto ao grau de autonomia que a agência tem, uma vez que esses diretores podem ter sido nomeados com o propósito de capturar a agência.

Além disso, o conselho diretor deliberará sobre as matérias de sua competência com, no mínimo, três votos convergentes, cabendo ao diretor geral o voto de qualidade. Ademais, os membros do conselho diretor estarão sujeitos à perda de mandato por descumprimento dos seus deveres funcionais ou por improbidade administrativa, com base em processo administrativo, na forma das leis que tratam das respectivas matérias. Portanto, com isso, verifica-se o poder desse conselho, bem como do seu diretor em relação à regulação das concessões no estado de São Paulo. Nesse caso, é possível que eles sejam capturados para atender aos interesses privados, sejam eles do governo do estado ou das concessionárias reguladas. Nessas circunstâncias, a eficiência do setor bem como a credibilidade do sistema de regulação no Estado ficam comprometidas, o que prejudica o interesse da iniciativa privada em investir em infraestrutura rodoviária.

Por fim, cabe ainda destacar a questão da autonomia financeira da agência. Apesar de estar claro no seu regimento que a ARTESP é uma autarquia dotada de autonomia financeira, acredita-se que, na prática, esta seja uma característica que não se verifica, o que pode facilitar a captura do agente regulatório. Tal situação pode ser creditada pelo que destacam Cardoso et al. (2012), segundo os quais, a ARTESP recebe uma parcela variável correspondente a $3 \%$ da receita bruta 
efetivamente obtida pela concessionária no mês anterior ao pagamento, sendo os valores pagos mensalmente de acordo com a demanda de cada trecho pedagiado. Portanto, quanto maiores as receitas obtidas pelas concessionárias, maiores os valores repassados à ARTESP, abrindo, essa relação, espaço para que a agência busque maximizar suas receitas agindo a favor da maximização das receitas da concessionária em detrimento da eficiência do setor.

Examinou-se também a atuação da $A G E P A R / P R$, responsável pela regulação de seis concessionárias que atuam no estado, quais sejam: Econorte, Viapar, Ecocataratas, Caminhos do Paraná, Rodonorte e Ecovia. A AGEPAR foi criada em 2002 e regulamentada somente em 2012. Nesse caso, na primeira década das concessões no Estado, as empresas atuaram sem um órgão regulador ativo, podendo ter havido espaço para uma atuação oportunista das empresas em busca de ganhos extranormais.

Conforme o Regimento Interno, a AGEPAR também é uma autarquia, sob regime especial, dotada de personalidade jurídica de direito público, vinculada ao Governo do Estado do Paraná e, orçamentariamente, à Secretaria de Estado de Infraestrutura e Logística. Pela sua natureza autárquica, a AGEPAR é caracterizada por independência decisória, autonomia administrativa, financeira, técnica, funcional e de poder de polícia, com as prerrogativas da Fazenda Pública, mandato fixo e estabilidade de seus dirigentes. Tais atributos são meios de garantir a independência decisória da agência, assegurando, com isto, que suas ações visem, unicamente, à eficiência do setor e à defesa do interesse da coletividade.

O órgão máximo da AGEPAR é o conselho diretor, órgão colegiado de caráter deliberativo, incumbido de exercer competências executivas e de direção. Ressalta-se que os membros do conselho diretor são indicados pelo governador do Estado e por ele nomeados. Mais uma vez, esse é um ponto frágil contra o combate à captura, uma vez que a nomeação do governador pode ser traduzida em ações oportunistas. O mandato do diretor é de três anos, admitida uma única recondução, sendo que ele permanecerá no exercício de suas funções após o término de seu mandato até que seu sucessor seja nomeado e empossado. Portanto, os diretores e conselheiros somente perderão seus mandatos nas seguintes situações: i) renúncia; ii) condenação judicial transitada e julgada; iii) decisão terminativa em processo administrativo disciplinar; iv) ausência a três reuniões consecutivas ou a cinco reuniões alternadas por ano, independentemente da justificativa apresentada.

Mesmo sob certa estabilidade do cargo, ainda assim é possível que os membros do conselho diretor e o próprio diretor da agência atuem em prol de interesses particulares, pois, às vezes, é mais vantajoso receber os benefícios dos particulares, que são o governo e as concessionárias, do que continuar nos respectivos cargos na agência. Além disso, mais uma vez não consta no regimento interno a questão da autonomia financeira, a não ser as garantidas para autarquias. Portanto, a agência pode atuar em prol do seu patrocinador e não necessariamente na busca da eficiência e do atendimento ao interesse público.

Outra agência analisada neste estudo foi a AGERGS/RS, instituída em 1997. Segundo o Regimento Interno, a AGERGS é autarquia sob regime especial, dotada de independência decisória e autonomia financeira, funcional e administrativa, e tem por finalidade regular os serviços públicos delegados, em conformidade com suas competências legais. Assim como nas demais agências analisadas, o conselho 
superior é o órgão colegiado de direção superior, sendo composto por sete membros, intitulados conselheiros, nomeados pelo governador para mandato de quatro anos, vedada a recondução, após aprovação de seu nome pela Assembleia Legislativa. Já a presidência da AGERGS será exercida pelo conselheiro-presidente, eleito pelos membros do conselho superior. Além disso, o conselheiro-presidente poderá ser assessorado por até dois especialistas, designados assessores, escolhidos livremente.

Novamente, o que se vê é uma estrutura organizacional em que o conselho superior bem como o conselheiro-presidente têm grande poder de decisão, podendo ser alvo de investidas tanto do governo quanto das concessionárias no que concerne à ação de captura regulatória. Ademais, não há sinalização clara de autonomia financeira no regimento da agência, fator determinante para sua atuação independente. Com isso, acredita-se que a AGERGS, em determinadas circunstâncias, possa ter sua atuação distorcida pelo poder privado e passar a atuar em benefício próprio e de seus conselheiros, quando eles optarem por defender interesses privados e não os da coletividade e aqueles que garantem a eficiência do setor.

Por fim, cabe destacar que a AGERGS foi a primeira agência de regulação de serviços públicos criada em âmbito estadual e coube a ela, até dezembro de 2013, a regulação dos contratos de sete concessionárias: Brita, Convias, Coviplan, Metrovias, Rodosul, Santa Cruz e Sulvias. Após dezembro de 2013, essas praças passaram à administração da Empresa Gaúcha de Rodovias - EGR e a AGERGS focou suas atividades em regular outros serviços públicos, como o transporte rodoviário de passageiros, energia elétrica, saneamento, estações rodoviárias e travessias hidroviárias.

\section{CARACTERÍSTICAS GERAIS DA REGUALAÇÃO NO SETOR DE RODOVIAS E O PROBLEMA DA CAPTURA REGULATÓRIA5:}

Como destacado na seção anterior e de acordo com o estudo de Amaral (2008), o simples fato de o regulador ser dotado de independência não afasta a necessidade de controle por parte da própria administração, exercido de forma direta pelo Ministro de Estado responsável pelo setor regulado e, indiretamente, pelo chefe do Poder Executivo, em razão da possibilidade de captura. Sendo assim, acredita-se que as agências sofram controle específico, visto que se submetem aos três Poderes do Estado, como também ao TCU, órgão integrante do Poder Legislativo Federal.

No tocante a essa questão, de acordo com Grotti (2012), visto que a independência das agências está também respaldada na autonomia decisória, não é possível afirmar que essa entidade, vinculada ao ministério supervisor, possa fugir da orientação e coordenação do ministério de Estado da área respectiva, no caso, o Ministério dos Transportes. Assim, tal fato se traduz em uma limitação à independência da agência e abre a possibilidade de interferência política.

\footnotetext{
${ }^{5} \mathrm{O}$ conceito de "captura" refere-se à tendência de os órgãos reguladores serem dominadas pelos interesses daqueles agentes que deveriam regular, ou seja, as empresas prestadoras de serviços públicos e também do Governo ao qual se vincula a agência.
} 
Contudo, conforme destaca Grotti (2012), o Poder Executivo não tem a faculdade de mudar as decisões concretas, nem as normas editadas pela agência. Seus atos não podem ser revistos ou alterados pelo Poder Executivo, salvo na vigência de expressa previsão legal. Nessas circunstâncias, dependendo do arranjo legal, há agências com alto grau de autonomia e outras com pouca ou nenhuma autonomia, ou seja, há poder de interferência maior ou menor do Executivo.

Quanto à interferência nas decisões da agência, o que cabe mencionar também, segundo Bagatin (2005), é que o fato de as agências reguladoras se apresentarem independentes torna-as mais suscetíveis à ocorrência de captura. Isso porque, diante da autonomia de que são dotadas, há condições propícias para que os responsáveis pela regulação passem a atuar estrategicamente, buscando segurança e estabilidade, neste caso, atuando em prol do poder concedente ou visando a auferir algum tipo de compensação por parte das empresas reguladas.

Além de situações em que há atuação estratégica dos responsáveis pelo exercício da regulação, existem características do setor regulado, como a concentração do mercado, que favorecem a questão da captura. No caso do setor de infraestrutura rodoviária, normalmente, os agentes econômicos que nele operam constituem um grupo formado por poucos integrantes, com interesses coesos.

No que tange a isso, as informações contidas no Quadro 1A (Anexo A) permitiram examinar a razão de concentração $\left(\mathrm{CR}_{4}\right)$ do setor para as quatro maiores concessionárias, medida em termos da extensão $(\mathrm{km})$ do trecho concedido ${ }^{6}$ (Tabela 1).

Tabela 1. Parcela de mercado das quatro maiores empresas/Grupos que controlam concessões de rodovias no Brasil, medida em termos de tamanho do trecho concedido, informações de 2014

\begin{tabular}{cccc}
\hline Grupo investidor & $\begin{array}{c}\text { Número de } \\
\text { concessões }\end{array}$ & $\begin{array}{c}\text { extensão do trecho } \\
\text { sob concessão }\end{array}$ & parcela de mercado \\
\hline CCR & 8 & 2078 & $14,24 \%$ \\
ECORODOVIAS & 5 & 1566 & $10,70 \%$ \\
ARTERIS/ABERTIS & 4 & 1493 & $10,23 \%$ \\
ATLANTIA BERTIN & 3 & 1119 & $7,66 \%$ \\
Total das 4 maiores & 20 & 6256 & $43 \%$ \\
\hline
\end{tabular}

Fonte: Elaboração própria.

${ }^{6} \mathrm{O} \mathrm{CR}_{\mathrm{k}}$ pode ser obtido pelo somatório da parcela de mercado das $\mathrm{k}$ maiores empresas, conforme $c R_{K}=\sum_{i=1}^{N} S_{i}$, em que Si se refere à parcela de mercado da empresa i, considerando as $\mathrm{N}$ empresas do mercado. De acordo com o Conselho Administrativo de Defesa Econômica, CADE, ao dominar $20 \%$ de um determinado mercado, uma empresa ou um grupo de empresas tem posição dominante neste mercado. Informações adicionais sobre o $C_{k}$ podem ser obtidas em Martin (1993). 
O que se verificou com essa simples análise foi que o setor está concentrado, uma vez que $43 \%$ do mercado está sob o domínio de quatro empresas ou grupos: CCR (14,24\%), Ecorodovias (10,7\%) Abertis/Arteris $(10,23 \%)$ e Atlantia Bertin (\%). Conforme o Quadro 1A (Anexo), se somados os trechos concedidos à Abertis/Arteris, Abertis/Bookfiel e Abertis/Arteris/Bookfiel, a empresa Abertis se torna uma gigante, pois, nesta situação, domina mais de $20 \%$ do mercado. Posto isso, é possível que a garantia da eficiência nos processos licitatórios fique comprometida pela possível pressão exercida por esses grupos de interesses, que podem agir em cartéis ou até mesmo usar do domínio econômico e influência política e exercer a captura regulatória de modo a impedir a entrada de novas empresas no setor nos processos licitatórios.

Além disso, de acordo com Pinto Junior e Mathias (2000), uma das consequências da captura do órgão regulador é o fato de ela poder acarretar perda de credibilidade da agência como mediadora de conflitos, o que acaba por gerar aumento dos custos e redução da eficiência da regulação. Conforme Oliveira et al. (2012), ainda que não seja fácil a demonstração de que o problema da captura é real, é certo que existem características que denunciam sua ocorrência. Segundo os autores, podem ser apontados como elementos preocupantes e, possivelmente, indicativos da ocorrência da captura a baixa qualidade, o preço alto e a baixa taxa de universalização dos serviços prestados por concessionárias, que são objeto de atuação das agências reguladoras.

Além desses pontos levantados por Oliveira et al. (2012), destacam-se ainda questões relativas à capacidade técnica da decisão das agências, elementos fundamentais para a garantia da eficiência no Setor. Conforme análise do Quadro 2A (Anexo A), é possível verificar, no caso da ANTT, que o conselho diretor indicado pelo presidente da república é composto por membros que apresentam qualificação profissional na área, sendo o diretor geral um administrador e os outros, conselheiros, especialistas em regulação, mestres em economia e especialistas em transportes. Contudo, existem funções importantes da ANTT desempenhadas por sociólogos e engenheiros civis, caso da gerência de atos normativos e outorgas da superintendência de exploração de infraestrutura rodoviária e da gerência de fiscalização e controle operacional de rodovias. Nesse caso, a falta de qualificação técnica e a experiência profissional na área podem levar à ineficiência das decisões da agência.

Quanto às agências estaduais, notou-se que, no que tange ao conselho diretor da ARTESP, o diretor geral é também administrador, assim como outros membros que ocupam cargos estratégicos como diretoria de controle econômicofinanceiro, diretoria de operações e diretoria de investimentos. Portanto, alguns membros do corpo técnico da ARTESP não têm formação específica na área de transportes, o que pode ser um ponto falho na garantia das decisões da agência.

No caso da AGETRANSP, agência do Rio de Janeiro, chama atenção o fato de o conselho diretor, órgão máximo da agência, ser dirigido por ex-executivo de concessionária de transporte do Estado, e demais membros do conselho serem pedagogos, ex-deputados e ex-chefes de gabinetes de políticos. Tal fato leva a suspeitar que essas indicações do governo do Estado não se pautaram na competência técnica, mas, sim, em algum critério que não zela pela atuação imparcial da agência, neste caso, sendo possível que a AGETRANSP esteja sob 
forte possibilidade de captura regulatória, o que traz sérias implicações para a atuação em prol da eficiência das concessões sob sua fiscalização.

Quanto à agência da Bahia, a AGERBA, a situação parece não ser diferente do que ocorre na AGENTRANSP, uma vez que o diretor geral é um advogado e os demais membros do conselho são administradores e ex-políticos. Ou seja, um corpo técnico sem qualificação adequada para as funções que desempenha. No que diz respeito à $A G E P A R$, agência do Paraná, seu diretor geral é um geólogo e isto novamente sinaliza que a indicação dos governos pode não estar pautada na competência técnica. Entretanto, há de se considerar que o diretor de tarifas e estudos econômicos e financeiros da agência é um economista com atuação em diversos setores do Departamento de Estradas de Rodagem - DER. No que concerne ao conselho diretor da AGERGS, ele é presidido por um contador e os demais conselheiros são bacharéis em ciências jurídicas, advogados e engenheiros mecânicos. Alguns têm experiência em setores regulados, inclusive, tendo ocupado funções em órgãos como o Departamento Nacional de Estradas de Rodagem DNER.

Diante dessas circunstâncias, o que se notou com a análise das informações sobre o corpo técnico dos conselhos diretores, órgãos máximos das agências, é que, diferentemente da indicação do governo federal para os integrantes do conselho da ANTT, as indicações dos governos estaduais não deram a devida importância para a capacidade técnica como critério de escolha e isto deixa a decisão desses membros vulnerável à pressão de grupos de interesses. Nesse sentido, o problema da captura coloca-se como um risco que pode, ou não, ocorrer, e que está ligado à decisão de se regular determinado setor econômico por meio de agências reguladoras independentes. Ademais, entende-se que esse risco deve ser prevenido, visto que a ocorrência da captura pode reduzir os padrões de eficiência almejados para o setor.

Além disso, o fato de os contratos de concessão serem firmados em um contexto de longo prazo e com informação assimétrica aumenta a possibilidade de ação oportunista da concessionária, uma vez que, para o órgão regulador, o acesso a informações, como as de custo e fluxo de demanda, é custoso e, muitas vezes, impossível. Ademais, falhas na legislação e no marco regulatório como um todo permitem expertises dos agentes, que se aproveitam do fato de que nem sempre as agências reguladoras atuam com real autonomia financeira e decisória. Portanto, diante dessas limitações do sistema regulatório, nem sempre é possível garantir a exploração econômica das rodovias, respeitando os interesses privados e públicos.

\section{CONCLUSÃO}

As análises realizadas neste estudo indicam que a participação das agências no setor pode contribuir para a eficiência das concessões, pois são várias as funções que tais agências desempenham. Logo, isso aumenta a preocupação com as questões inerentes aos problemas do agente-principal (risco moral e seleção adversa), à captura regulatória, independência decisória e autonomia financeira, que levam a influências políticas nas decisões das agências. Além disso, esses problemas são um aspecto depreciativo da ação regulatória, uma vez que levam à 
descrença desses órgãos, à ineficiência e à redução da participação privada no setor.

De modo geral, o que se pode inferir foi que, apesar de as agências terem sido criadas em forma de autarquias dotadas de independência financeira e administrativa, inclusive com poderes normativos, há pontos importantes de frouxidão no regime de atuação desses órgãos, principalmente os ligados à nomeação/indicação dos membros dos conselhos superiores pelos respectivos governos e à subordinação orçamentária. Tais aspectos, na verdade, acabam por desmentir a completa autonomia financeira e administrativa de que se gabam os entes reguladores, e ainda sinalizam para a possibilidade da captura regulatória e influência política.

Nesse contexto, o mecanismo da regulação convencional, via agências, apesar de importante para incentivar a oferta eficiente do serviço de infraestrutura rodoviária, mostra-se insuficiente para aumentar a eficiência no setor, uma vez que esses órgãos estão vulneráveis tanto em relação aos problemas apontados pelo modelo agente-principal, principalmente os inerentes à captura regulatória, quanto à falta de independência decisória e autonomia financeira.

Obviamente, tais problemas apresentados pelas agências poderiam ser mitigados se houvesse um marco regulatório com leis claras e capazes de criar o ambiente propício ao sucesso regulatório. Cabe destacar também que a existência das agências reguladoras pode, ao menos, resguardar, em parte, o interesse público. Além do mais, a experiência acumulada pela agência com o desempenho de seu trabalho pode resultar na viabilização de mecanismos mais seguros e eficazes de regulação, desde, é claro, que seu funcionamento tenha, de fato, como eixo fundamental, o interesse público.

Além disso, faz-se necessário criar uma cultura de transparência e controle social sobre as ações das agências, de modo que elas tenham que responder pelo desvio de seus objetivos fundamentais, que, basicamente, consistem do zelo pelo interesse da coletividade. Por fim, pensar que o sistema de mercado (ausência da regulação), no caso de concessões de rodovias, está livre dos problemas enfrentados pelas agências seria equivocado; mesmo porque, em processos de licitação, é provável haver espaço para as expertises proporcionadas pela assimetria de informação e pela possibilidade de captura e atuação em conluio por parte das empresas.

Portanto, para o caso de concessões de rodovias no Brasil, a ação regulatória, via agências, apesar de carecer de reformulação e aparato legal, é importante para a garantia da eficiência, visto que o livre mercado (leilão) por si só não contornaria os problemas da relação agente-principal no setor de concessões no Brasil, que é concentrado e permite ação oportunista no momento das licitações.

\section{REFERÊNCIAS}

ARROW, K. J. Principal and agents: the structure of American business. Boston: Harvard Business School Press, 1985.

AMARAL, A. S. Princípios Estruturantes das Agências Reguladoras e os mecanismos de Controle. Rio de Janeiro. Editora: Lumen Juris, 2008. v. 1. 134p . 
BAGATIN, A.C. O problema da captura do regulador e o seu controle pelo Poder Judiciário: comentários a acórdão do Tribunal Regional Federal da $5^{\text {a }}$ Região. Revista de Direito Público da Economia, v. 11, p. 211-219, 2005.

BRASIL. TRIBUNAL DE CONTAS DA UNIÃO. O controle externo das agências reguladoras: questões relevantes sobre o setor de rodovias, de ferrovias e de transporte rodoviário de passageiros / Tribunal de Contas da União; apresentação Adylson Motta. Brasília: TCU, Secretaria de Fiscalização de Desestatização, 2005.

BRASIL. TRIBUNAL DE CONTAS DA UNIÃO. Seminário Desenvolvimento de Infraestrutura de Transportes no Brasil: perspectivas e desafios (2006) : Brasília, DF). Desenvolvimento de infraestrutura de transportes no Brasil: perspectivas e desafios. Brasília: TCU, 2007.

CÂMARA, Marianne Trindade. Uma metodologia para avaliação de desempenho em infra-estruturas de transporte concedidas: aplicação às concessões de rodovias federais brasileiras. 2006. 226 f. Dissertação (Mestrado em Transportes)Universidade de Brasília, Brasília, 2006.

CHADWICK. E. Results of Different principles of Legislation in Europe: Of Competition for the Field as Compared with Competition within the Field of Service. Journal of the Royal Statistical Society, series A22, pp. 381-420. 1859.

CLEGG, S. R.; HARDY, C.; NORD, W. R. Handbook of organization studies. London: Sage Publications, 1996.

CARDOSO, A. B. C.; AQUINO, A. C. B.; ANUATTI NETO, F.; CARDOSO, R. L. Dinâmica dos ajustes contratuais em concessão de rodovias no estado de São Paulo. Revista de Administração Pública (Impresso), v. 46, p. 1295-1315, 2012.

CREW, M. A.; KLEINDORFER, P. R. Regulatory Economics: Twenty Years of progress? Center for Research in Regulated Industries. Rutgers University. Estados Unidos. 2002.

DEMSETZ, H. Why regulate utilities? Journal of Law and Economics. Chicago, v. 11, p. 55-66, april. 1968.

DI PIETRO, M. S. Z. Limites da Função Reguladora das Agências Diante do Princípio da Legalidade. In: Di Pietro (org) Direito Regulatório: Temas Polêmicos. Editora Fórum, 2 ed., Brasília. 2004.

EKELUND, R. B.; HÉBERT, R, F. the Proto-History of franchise Bidding. Southern Economic Journal, v. 48, pp. 464-74, October. 1981.

GROTTI, D. A. M. As agências reguladoras. Revista dos Tribunais, v. VI, p. 893930, 2012. 
GUERRA, S. A. S. Agências Reguladoras: Da organização Administrativa Piramidal à Governança em Rede. Belo Horizonte: Editora Fórum, 2012. 238p.

HATCH, M. J. Organization theory: modern symbolic and postmodern perspectives. New York: Oxford University Press, 1997.

JENSEN, M.; MECKLING, W. Theory of the firm: managerial behavior, agency costs and capital structure. Journal of Financial Economics, v. 3, p. 305-360, 1976.

MARTIN, S. Industrial economics: economic analysis and public policy. 2. Ed. New Jersey: Prentice Hall, 1993.

OLIVEIRA, J. ; PEREZ FILHO, A.; WOOD, S. Q. Agências Reguladoras e o fenômeno da captura. Pensar (UNIFOR), v. 17, p. 195-209, 2012.

PIRES, J. C.; PICCININI, M. S. A regulação dos setores de infraestrutura no Brasil. In: A economia brasileira nos anos 90. BNDES, Rio de Janeiro. 1999.

PINTO JUNIOR, H. Q.; MATHIAS, M. C. P. P. Assimetria de Informações e Problemas Regulatórios. 2000. Disponível em:

<http://www.ppge.ufrgs.br/GIACOMO/arquivos/eco02036/pintojr-pires2000.pdf> Acesso em 20 fev. 2014.

POSNER, R. A. The Appropriate Scope of Regulation in the Cable Television Industry. The Bell Journal of Economics. v. 3, p. 98-129, spring. 1972.

PRADO, M. M. Agências Reguladoras, Independência e Desenho Institucional. In: INSTITUTO TENDÊNCIAS DE DIREITO E ECONOMIA (Org.). Agências reguladoras. p. 125-164, São Paulo. 2005.

VERON, A.; CELLIER, J. Participação privada no setor rodoviário no Brasil. Evolução recente e próximos passos. Transport Papers Series TP-30, World Bank, Washington, D.C., USA, 2010.

VILLALBA, E. T.; FADUL, E. M. C. ; SILVA, L. P. A atuação da AGERBA na Regulação do Serviço de Gás Canalizado no Estado da Bahia: Contradições de uma Agência Reguladora. Revista de Administração e Contabilidade da FAT, v. 2, p. 28-45, 2010.

VISCUSI, W. K.; VERNON, J. M.; HARRINGTON, J. E. Economics of regulation and antitrust. 3 ed. Cambridge, Massachussets Institute of Technology, 2000.

WILLIAMSON, O.E. Franchising Bidding for Natural Monopolies: in general and with respect to CATV. The Bell Journal of Economics. v. 7, p. 73-104. spring. 1976. 
Submetido em 29/04/2015

Aprovado em 08/12/2015

\section{Sobre as autoras}

\section{Graciela Aparecida Profeta}

Doutorado em Economia Aplicada pela Universidade Federal de Viçosa. Professora Adjunta do Departamento de Economia da Universidade Federal Fluminense - Campos dos Goytacazes-RJ-MG. Endereço para correspondência: Departamento de economia- R. José do Patrocínio, 71 - Centro, Campos dos Goytacazes - RJ, 28010-385

E-mail: graciela_profeta@yahoo.com.br

\section{Viviani Silva Lírio}

Doutorado em Economia Aplicada pela Universidade Federal de Viçosa. Professora Associada, Departamento de Economia Rural da Universidade Federal de Viçosa-MG.

Endereço para correspondência: Departamento de Economia Rural- Avenida Peter Henry Rolfs, $\mathrm{s} / \mathrm{n}^{\circ}$ - Campus Universitário. 36570-900 Viçosa - MG - Brasil.

E-mail:vslirio@ufv.br

\section{Elke Silva Santos}

Advogada.

Endereço para correspondência Rua Oswaldo Tavares, $n^{\circ} 22$, apto 102, Flamboyante-Campos dos Goytacazes. 29015190-000 - RJ - Brasil.

E-mail: elkesilvasantos@yahoo.com.br 


\section{APÊNDICES}

Quadro 1A. Parcela de Mercado dos grupos investidores de concessões de rodovias no Brasil em relação ao tamanho do trecho concedido, dados de 2014

\begin{tabular}{|c|c|c|c|}
\hline Concessionárias (DMU) & $\mathrm{km}$ & $\begin{array}{c}\text { Parcela de } \\
\text { mercado }\end{array}$ & Grupo investidor \\
\hline Viabahia & 680 & $4,7 \%$ & Isolux Corsán (55\%) + Encalso (23\%)+Infravix (22\%) \\
\hline Ecosul & 623 & $4,3 \%$ & Ecorodovias $(90 \%)$ \\
\hline Rodonorte - PR & 568 & $3,9 \%$ & $\operatorname{CCR}(85 \%)$ \\
\hline Fernão Dias & 562 & $3,9 \%$ & Arteris $(100 \%)$ \\
\hline Viapar-PR & 546 & $3,7 \%$ & Grupo 2 de investidores \\
\hline Metrovias- RS & 533 & $3,7 \%$ & AEGEA Rodovias (75.5\%) + TBPAR (24\%) \\
\hline SPVIAS-SP & 515 & $3,5 \%$ & CCR (100\%) \\
\hline Ecocataratas-PR & 458 & $3,1 \%$ & Ecorodovias $(100 \%)$ \\
\hline Cart-SP & 443 & $3,0 \%$ & Invepar (100\%) \\
\hline Triangulo do Sol -SP & 442 & $3,0 \%$ & Atlantia Bertin (100\%) \\
\hline Viarondon-SP & 413 & $2,8 \%$ & Brvias (100\%) \\
\hline Planalto Sul & 412 & $2,8 \%$ & Abertis (51\%) + Brokfiel (49\%) \\
\hline Rodovias do Tietê- SP & 406 & $2,8 \%$ & $A B$ concessões $(50 \%)+$ Ascendi $(50 \%)$ \\
\hline Litoral Sul & 405 & $2,8 \%$ & Abertis (51\%) + Brokfiel (49\%) \\
\hline Novadutra & 402 & $2,8 \%$ & CCR $(100 \%)$ \\
\hline Régis Bittencourt & 401 & $2,7 \%$ & Abertis $(51 \%)+$ Brokfiel (49\%) \\
\hline Intervias- SP & 375 & $2,6 \%$ & Arteris/abertis (100\%) \\
\hline Nascentes - MG & 371 & $2,5 \%$ & Atlantia Bertin (100\%) \\
\hline Renovias-SP & 345 & $2,4 \%$ & ENCALSO $(60 \%)+$ Grupo CC $(40 \%)$ \\
\hline Econorte-PR & 340 & $2,3 \%$ & Triunfo $(100 \%)$ \\
\hline Sulvias- RS & 328 & $2,2 \%$ & AEGEA Rodovias (75.5\%) + TBPAR (24\%) \\
\hline Transbrasiliana & 321 & $2,2 \%$ & Brvias (100\%) \\
\hline Fluminense & 320 & $2,2 \%$ & Arteris/Abertis (100\%) \\
\hline Autoban-SP & 316 & $2,2 \%$ & CCR $(100 \%)$ \\
\hline Autovias - SP & 316 & $2,2 \%$ & Abertis/Arteris (51\%) + Brookfiel (49\%) \\
\hline Colinas-SP & 306 & $2,1 \%$ & Atlantia Bertin (100\%) \\
\hline Rota das Bandeiras-SP & 297 & $2,0 \%$ & Odebrecht (100\%) \\
\hline Coviplan - RS & 250 & $1,7 \%$ & Grupo 4 de investidores \\
\hline Vianorte-SP & 236 & $1,6 \%$ & Arteris/Abertis (100\%) \\
\hline Centrovias - SP & 218 & $1,5 \%$ & Abertis $(51 \%)+$ Brookfiel $(49 \%)$ \\
\hline $\mathrm{CLN}-\mathrm{BA}$ & 217 & $1,5 \%$ & Grupo 1 de investidores \\
\hline Santa Cruz- RS & 207 & $1,4 \%$ & Serveng $(10 \%)$ \\
\hline Rodovia do Aço & 200 & $1,4 \%$ & Acciona $(100 \%)$ \\
\hline Convias-RS & 191 & $1,3 \%$ & AEGEA Rodovias $(75,5 \%)+$ TBPAR $(24 \%)$ \\
\hline Concer & 180 & $1,2 \%$ & Triunfo $(62.5 \%)$ \\
\hline Ecovias dos Imigrantes - SP & 176 & $1,2 \%$ & Ecorodovias (100\%) \\
\hline Ecovia - PR & 175 & $1,2 \%$ & Ecorodovias $(100 \%)$ \\
\hline Viaoeste-SP & 168 & $1,2 \%$ & CCR $(100 \%)$ \\
\hline TEBE-SP & 155 & $1,1 \%$ & TORC $(50 \%)+$ ECB $(50 \%)$ \\
\hline CRT & 142 & $1,0 \%$ & Vários \\
\hline Brita-RS & 142 & $1,0 \%$ & Grupo 3 de investidores \\
\hline Ecopistas-SP & 134 & $0,9 \%$ & Ecorodovias $(100 \%)$ \\
\hline Rodosul-RS & 132 & $0,9 \%$ & J Mulucelli (46\%) + Encalso Construções (24\%) \\
\hline Concepa & 121 & $0,8 \%$ & Triunfo $(100 \%)$ \\
\hline Vialagos-RJ & 56 & $0,4 \%$ & CCR $(100 \%)$ \\
\hline Rodoanel Oeste - SP & 30 & $0,2 \%$ & CCR $(95 \%)+$ Encalso $(5 \%)$ \\
\hline Ponte & 23 & $0,2 \%$ & CCR $(100 \%)$ \\
\hline total & 14597 & $100 \%$ & \\
\hline
\end{tabular}

Fonte: Elaboração própria, com base em informações da ANTT e da ABCR. 
Quadro 2A. Capacitação técnica dos membros dos Conselhos Diretores das Agências de regulação de rodovias no Brasil, 2014.

\begin{tabular}{|c|c|c|}
\hline \multicolumn{3}{|c|}{ ANTT-FEDERAL } \\
\hline NOME & CARGO & TITULAÇÃO/EXPERIÊNCIA PROFISSIONAL \\
\hline Jorge Luiz Bastos & Diretor Geral & $\begin{array}{l}\text { Graduado em Administração. Pós-Graduação em Gestão } \\
\text { de Projetos. }\end{array}$ \\
\hline $\begin{array}{l}\text { Ana Patrizia Gonçalves } \\
\text { Lira }\end{array}$ & $\begin{array}{l}\text { Diretoria interina } \\
\text { (conselheira) }\end{array}$ & $\begin{array}{l}\text { Especialista em regulação da ANTT. Gerente executiva e } \\
\text { membro da Comissão de Ética da ANTT. }\end{array}$ \\
\hline $\begin{array}{l}\text { Carlos Fernando do } \\
\text { Nascimento }\end{array}$ & $\begin{array}{l}\text { Diretoria interina } \\
\text { (conselheiro) }\end{array}$ & $\begin{array}{l}\text { Especialista em Regulação de Transportes Terrestres. } \\
\text { Especialista em Regulação de Serviços de Transportes } \\
\text { Terrestres da ANTT. }\end{array}$ \\
\hline $\begin{array}{l}\text { Natália Marcassa de } \\
\text { Souza }\end{array}$ & Diretoria interina & $\begin{array}{l}\text { Mestre em Economia. Especialista em Transportes. } \\
\text { Gerente de Regulação e Outorga da Exploração de } \\
\text { Rodovias. }\end{array}$ \\
\hline Nara Kholsdorf & $\begin{array}{l}\text { Gerência de Atos } \\
\text { Normativos e de } \\
\quad \text { Outorgas }\end{array}$ & $\begin{array}{l}\text { Doutora em Sociologia pela USP. Atualmente é gerente } \\
\text { de atos normativos e de outorgas fiscalização da ANTT. }\end{array}$ \\
\hline Viviane Esse & $\begin{array}{l}\text { Superintendência de } \\
\text { Exploração de } \\
\text { Infraestrutura Rodoviária }\end{array}$ & Engenheira Civil \\
\hline \multicolumn{3}{|c|}{ ARTESP-SÃO PAULO } \\
\hline Karla B. Trindade & Diretora geral & Graduada em Administração Pública pela FGV. \\
\hline $\begin{array}{l}\text { Theodoro de Almeida } \\
\text { Pupo Jr }\end{array}$ & $\begin{array}{l}\text { Diretoria de } \\
\text { Investimentos }\end{array}$ & $\begin{array}{l}\text { Engenheiro e Administrador de Empresas pela } \\
\text { Universidade Mackenzie. Atualmente é Diretor de } \\
\text { Investimentos da ARTESP }\end{array}$ \\
\hline Giovanni Pengue Filho & Diretoria de Operações & Graduado em Administração com MBA em Marketing. \\
\hline \multicolumn{3}{|c|}{ AGETRANSP - RIO DE JANEIRO } \\
\hline César Mastrângelo & $\begin{array}{l}\text { Presidente do Conselho } \\
\text { Diretor }\end{array}$ & $\begin{array}{l}\text { Até o início de 2013, era diretor de Relações } \\
\text { Institucionais do Metrô Rio (concessionária) }\end{array}$ \\
\hline Lucineide C. March & Conselheira & Pedagoga e ex-chefe de gabinete do presidente da Alerj. \\
\hline Aparecida Gama & Conselheira & Ex-deputada pelo PMDB \\
\hline Arthur V. Bastos & Conselheiro & Ex-chefe de gabinete da Secretaria da Casa Civil. \\
\hline \multicolumn{3}{|c|}{ AGERBA-BAHIA } \\
\hline Eduardo H. M.Pessôa & Diretor executivo & Advogado \\
\hline $\begin{array}{l}\text { Paulo S. P. Magalhães } \\
\text { Júnior }\end{array}$ & Diretor de Tarifas & $\begin{array}{l}\text { É formado em administração de empresas, com pós- } \\
\text { graduação em marketing e políticas públicas. Ex- } \\
\text { vereador. }\end{array}$ \\
\hline $\begin{array}{l}\text { Guilherme de Castro } \\
\text { Lino Bonfim }\end{array}$ & Diretor de Fiscalização & Advogado \\
\hline \multicolumn{3}{|c|}{ AGEPAR-PARANÁ } \\
\hline $\begin{array}{l}\text { José Alfredo Gomes } \\
\text { Stratmann }\end{array}$ & $\begin{array}{l}\text { Presidente e Diretor de } \\
\text { Fiscalização e Qualidade } \\
\text { de Serviços }\end{array}$ & $\begin{array}{l}\text { Formado em Geologia pela UFRGS. Foi Diretor } \\
\text { Administrativo-financeiro do DER. }\end{array}$ \\
\hline $\begin{array}{l}\text { Ney Teixeira de Freitas } \\
\text { Guimarães }\end{array}$ & $\begin{array}{l}\text { Diretor de Tarifas e } \\
\text { Estudos Econômicos e } \\
\quad \text { Financeiros }\end{array}$ & $\begin{array}{l}\text { Bacharel em Ciências Econômicas pela Universidade } \\
\text { Católica do Paraná. Ocupou diversas funções no DER, } \\
\text { assessorando e coordenando programas. }\end{array}$ \\
\hline \multicolumn{3}{|c|}{ AGERGS-RIO GRANDE DO SUL } \\
\hline NOME & CARGO & TITULAÇÃO/EXPERIÊNCIA PROFISSIONAL \\
\hline $\begin{array}{l}\text { Carlos Felisberto Garcia } \\
\text { Martins }\end{array}$ & Conselheiro-Presidente & Graduação em Ciências Contábeis. \\
\hline Ayres Luiz Apolinário & $\begin{array}{l}\text { Conselheiro Vice- } \\
\text { Presidente }\end{array}$ & $\begin{array}{l}\text { Formado em Ciências Jurídicas e Sociais. Foi presidente } \\
\text { do Serviço Autônomo de Saneamento de Pelotas (Sanep) } \\
\text { e assessor especial da Secretaria de Infraestrutura e } \\
\text { Logística do Estado. }\end{array}$ \\
\hline $\begin{array}{l}\text { Juarez Monteiro } \\
\text { Molinari }\end{array}$ & Conselheiro & Advogado e Médico. \\
\hline
\end{tabular}

Fonte: Elaboração própria, com base em informações disponíveis nas páginas da internet das agências, 2014. 